\title{
Determination of Clopidogrel Carboxylic Acid in Human Plasma by LC-MS/MS
}

\author{
Mohamed El-Husseiny El-Sadek ${ }^{1}$, Samia Mahmoud Moustafa ${ }^{2}$, Hussien Omar Kadi ${ }^{3}$, \\ Abdul Moneim Ali Al-Hakami ${ }^{2}$ \\ ${ }^{1}$ Faculty of Pharmacy, Zagazig University, Zagazig, Egypt \\ ${ }^{2}$ Faculty of Pharmacy, Suez Canal University, Suez, Egypt \\ ${ }^{3}$ Faculty of Medicine, Sana' a University, Sana'a, Yemen \\ E-mail:alhakami2@gmail.com \\ Received April 2, 2011; revised May 12, 2011; accepted May 19, 2011
}

\begin{abstract}
Background: Clopidogrel, is a thienopyridine derivative labeled for use to prevent thrombosis after coronary artery stenting. Pharmacokinetics of clopidogrel is studied indirectly by quantification of carboxylic acid which is a major metabolite of Clopidogrel. Objective: The aim of this work is to develop and validate a rapid, simple and sensitive LC/MS/MS assay method for the determination of Clopidogrel carboxylic acid in human plasma using Clopidogrel-D4-carboxylic acid as internal standard. Methods: Analytes was extracted from $200 \mu \mathrm{l}$ of plasma by a simple liquid-liquid extraction using diethyl ether - n-hexane (80:20, v/v). The chromatographic separations were achieved on a C18 column using Methanol, de-ionized water and formic acid as a mobile phase at flow rate of $0.5 \mathrm{ml} /$ minute. Analysis was monitored by multiple reactions monitoring mode based on $\mathrm{m} / \mathrm{z}$ transition of $308.10 \rightarrow 113$ for Clopidogrel carboxylic acid and $312.10 \rightarrow 129$ for internal standard. Result: The method had a total run time of about 4 minutes. The lower limit of quantification (LLOQ) was $25 \mathrm{ng} / \mathrm{ml}$ showing good linearity over the working range of $25-3000 \mathrm{ng} / \mathrm{ml}(\mathrm{r} \geq 0.999)$. The intra- and inter day accuracies were $90 \%-98 \%$ and $92.138 \%-96.889 \%$ respectively (deviation within acceptable range $\leq 10 \%$ ). Conclusion: It was shown that this method is suitable for pharmacokinetic study following oral administration of Clopidogrel and can be successfully applied to the therapeutic drug monitoring of Clopidogrel in Clopidogrel-treated patients.
\end{abstract}

Keywords: Clopidogrel, Clopidogrel Carboxylic Acid, Liquid Chromatography, Tandem Mass Spectrometry

\section{Introduction}

Clopidogrel hydrogen sulfate (Figure 1), methyl $(+)-(S)$ $\alpha$-(o-chlorophenyl)-6,7-dihydrothieno[3,2-c]pyridin-5(4 $H$ )-acetate hydrogen sulfate, is a novel thienopyridine derivative that irreversibly blocks adenosine diphosphate (ADP) and is important in platelet aggregation, the cross-linking of platelets by fibrin. Clopidogrel is chemically related to Ticlopidine with superior side effects profile and dosing requirements [1-3].

The empirical formula of Clopidogrel bisulfate is $\mathrm{C}_{16} \mathrm{H}_{16} \mathrm{ClNO}_{2} \mathrm{~S}_{2} \mathrm{H}_{2} \mathrm{SO}_{4}$ and its molecular weight is 419.9 [4].

The molecule of clopidogrel contains an asymmetrical carbon at C-7 leading to the existence of two enantiomers $(R$ and $S)$. Studies showed that the active com- pound clopidogrel is the $S$-enantiomer $[5,6]$. Clopidogrel free base was unstable due to a labile proton in the chiral center and was susceptible to racemization and hydrolysis of methyl ester group [6,7].

The drug is rapidly but incompletely absorbed after oral administration and extensively metabolized to an active metabolite. The parent drug or its active metabolite remains undetectable in plasma. The major circulating compound, however, is an inactive carboxylic derivative, which is used to document the pharmacokinetic profile of clopidogrel [8].

The pharmacokinetic parameters of clopidogrel have been characterized by this inactive carboxylic acid metabolite in human plasma. An inactive carboxylic derivative represents $85 \%$ of circulating metabolites in human plasma [9]. The elimination half life of this compound is 


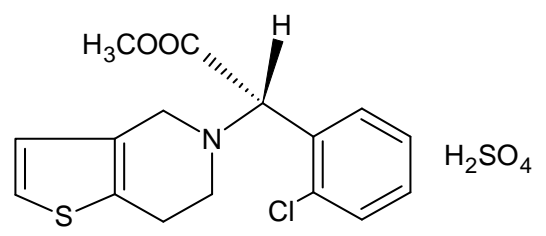

Figure 1. Chemical structure of clopidogrel bisulfate.

8 hours [10-12]. The platelet inhibition with clopidogrel lasts the lifespan of the platelet (7-10 days) [12-14].

Clopidogrel is inactive in vitro and hepatic biotransformation via the cytochrome P450 pathway, is essential for its in vivo antiplatelet activity [15]. The active metabolite, 5-thiol compound, is formed by the oxidation of clopidogrel to 2-oxoclopidogrel and subsequent hydrolysis. The active metabolite is highly labile and remains undetected in plasma $[6,16]$.

Clopidogrel and its metabolite bind reversibly to human plasma proteins $(94 \%$ - 98\%) and are excreted in both urine and feces with an elimination half- life of eight hours [17].

Clopidogrel is a potent, non-competitive inhibitor of adenosine diphosphate (ADP) induced platelet aggregation, irreversibly inhibiting the binding of ADP to its platelet membrane receptors [18]. The inhibition is specific and does not significantly affect cyclooxygenase or arachidonic acid metabolism $[19,20]$. Clopidogrel is the drug of choice to prevent thrombosis after coronary artery stenting $[21,22]$.

Quantification of carboxylic acid metabolite would be an indirect approach for studying the pharmacokinetics of clopidogrel [12,23-25].

The present study report a simple and sensitive liquid chromatography coupled to tandem mass spectrometric method (LC-MS/MS) for determination of Clopidogrel carboxylic acid in human plasma using Clopidogrel-d4-carboxylic acid as the internal standard. The developed method was successfully applied to a pharmacokinetic study after oral administration of Clopidogrel $(75 \mathrm{mg})$ to healthy volunteers.

\section{Materials}

\subsection{Reagents and Chemicals}

Clopidogrel carboxylic acid and Clopidogrel-d4-carboxylic acid were obtained from TRC. Methanol and Formic acid, HPLC grade and n-hexane were purchased from Merck, Germany. Diethyl ether was purchased from VWR, EC. De-ionized water was purchased from Milli.

\subsection{Instrumentation and LC/MS Conditions}

HPLC1100 Agilant from Agilant, Germany consisting of agilant 1100 binary pump, agilant 1100 autosampler and agilant1100 degasser. The chromatographic separations were achieved using a symmetryC18 column $(3.5 \mu \mathrm{m}$ $4.6 \times 75 \mathrm{~mm}$; Waters, USA). The mobile phase consisted of Methanol, de-ionized water and formic acid (75\%:25\%: $0.1 \%$ ). The flow rate of the mobile phase was set at 0.5 $\mathrm{ml} / \mathrm{min}$. the column oven temperature was $30^{\circ} \mathrm{C}$.

The HPLC system was coupled to an API 4000 MS/ MS triple-quadrupole system detector equipped with a turbo ion spray ionization (ESI) source ( Applied Biosystems MDS, SCIEX, Canada). The turbo ion spray ionization source was operated in a positive mode. The ion spray voltage was adjusted to $5500 \mathrm{~V}$. the mass spectrometer was operated at a unit resolution for both Q1 and Q3 in multiple reaction monitoring (MRM) mode. The transition of precursor to product ion was monitored at $308.10 \rightarrow 113$ for Clopidogrel carboxylic acid and $312.10 \rightarrow 129$ for internal standard. The method had a total run time 4 minutes.

\section{Methodology}

\subsection{Standard and Stock Solutions Preparation}

- Clopidogrel carboxylic acid stock solution $1 \mathrm{mg} / \mathrm{ml}$ prepared in methanol;

- Clopidogrel carboxylic acid working standard solution $100 \mu \mathrm{g} / \mathrm{ml}$ prepared in methanol;

- Clopidogrel-d4-carboxylic acid Stock Standard Solution $100 \mu \mathrm{g} / \mathrm{ml}$ prepared in methanol;

- Clopidogrel-d4-carboxylic acid working solution $1000 \mathrm{ng} / \mathrm{ml}$ prepared in de-ionized water;

\subsection{Calibration Curve and Quality Controls Spiking Preparation In Human Plasma}

The calibration standards of Clopidogrel carboxylic acid $25,50,100,200,500,750,1000,2000$ and $3000 \mathrm{ng} / \mathrm{ml}$, and 75,1500 and $2250 \mathrm{ng} / \mathrm{ml}$ quality controls were prepared by diluting the clopidogrel carboxylic acid solution $(100 \mu \mathrm{g} / \mathrm{ml})$ with drug-free human plasma. $200 \mu \mathrm{l}$ aliquots were transferred to $10 \mathrm{ml}$ glass tubes and stored at $-20^{\circ} \mathrm{C}$. Calibration standards of Clopidogrel carboxylic acid were extracted from all 9 concentration levels and assayed.

\subsection{Sample Extraction}

The internal standard solution (100 $\mu 1$ of Clopidogrel-d4-carboxylic acid $1000 \mathrm{ng} / \mathrm{ml}$ in de-ionized water) was added to each human plasma sample in glass tube, vortex for 30 seconds. Then $30 \mu \mathrm{l}$ of concentrated formic acid were added, vortex for 30 seconds. Six $\mathrm{ml}$ of $(20 \% \mathrm{n}$ - 
-hexane: $80 \%$ diethyl ether) were added, vortex for about 60 seconds followed by centrifugation for 5 minutes at 4000 r.p.m. The upper organic layer were decanted to a clean $10 \mathrm{ml}$ glass tubes and evaporated in water bath at $40^{\circ} \mathrm{C}$ under gentle stream of nitrogen gas. The residue was reconstituted with $200 \mu 1$ of mobile phase and $25 \mu 1$ was injected into LC/MS/MS

\section{Standardization and Calculation}

The method's linearity for Clopidogrel carboxylic acid determination in human plasma was confirmed for a range of concentrations between $(25-3000) \mathrm{ng} / \mathrm{ml}$ for Clopidogrel carboxylic acid respectively. Calibration curves were determined by a weighted quadratic regression equation $\left(Y=a_{2} X^{2}+a_{1} X+a_{0}\right)$ were used for Clopidogrel carboxylic acid. The best-fit peak area ratios vs. concentrations were used to back-calculate the concentrations, where y represents the (peak area of Clopidogrel carboxylic acid /peak area of internal standard) and a weighting of $1 / x\left(a_{0}, a_{1}, a_{2}\right.$, are the polynomial coefficients of quadratic equation). Chromatograms processing, data generation and concentrations back calculations were all performed by the Analyst software (Applied Biosystems, MDS, SCIEX, Canada). Summary of descriptive statistics was done by Excel spreadsheets.

\subsection{Method Validation}

Method validation was conducted in accordance with the ICH and USFDA guidelines and satisfies the requirements of applicable statutes and regulations[26,27]. Accordingly, the method validation was evaluated in terms of:

\subsubsection{Specificity, Selectivity and Matrix Effect}

The specificity of the method was determined by screening six different batches of human blank plasma and the injection of six LLOQ samples prepared using six different batches of human plasma. Specificity of the method was verified by the absence of any co-eluted peaks of endogenous plasma components at the retention times of the drug or the internal standard. Five out of six samples of LLOQ should meet the LLOQ acceptance criteria (not more than $20 \%$ deviation from the theoretical values). Specificity was conducted by analyzing 6 blank, zero and 6 LLOQ samples from six different plasma batches.

\subsubsection{Linearity}

For the determination of linearity, standard calibration curves of 9 points (non-zero standards) in addition to the blank and standard zero samples were prepared. On each day of the validation course, a calibration curve was prepared and its goodness of fit was calculated by least square linear regression equation, excluding the results of the blank and standard zero sample from the regression function. The concentrations of calibration standards were back calculated applying the obtained regression equation. At least $75 \%$ of non-zero standards, should meet the following acceptance criteria.

Not more than $20 \%$ deviation at LLOQ. Not more than $15 \%$ deviation for standards above the LLOQ.

\subsubsection{Accuracy and Precision}

Accuracy and precision evaluation was conducted over the first three days of the validation time course. At each day, QC samples were calculated employing the regression of the calibration curve prepared at the same day. The accuracy and precision deviation values should be within $20 \%$ for the LLOQ and $15 \%$ for the QC's above the LLOQ.

\subsubsection{Intra-day Accuracy and Precision}

The intra-day accuracy and precision of the assay was measured by analyzing four QC samples at each concentration level LLOQ, low QC, medium QC and high QC samples $(25,75,1500$ and $2250 \mathrm{ng} / \mathrm{ml})$ Clopidogrel carboxylic acid on three consecutive days with six replicate sample each day, where their concentrations were back calculated. The deviation of the mean from the nominal value serves as the measure of accuracy.

Acceptance Criteria: $\pm 20 \%$ for QCs at LLOQ and $\pm 15 \%$ for QCs at low, mid and high concentrations. Accepted ration is $67 \%$ of each level and $67 \%$ for the total.

\subsubsection{Inter-day Accuracy and Precision}

The inter day accuracy and precision was investigated at each concentration level $(25,75,1500$ and 2250$) \mathrm{ng} / \mathrm{ml}$ for Clopdogrel carboxylic acid over three days. Analysis was carried out using eighteen QC samples at each concentration level.

Acceptance criteria: $\pm 20 \%$ for QCs at LLOQ and $\pm 15 \%$ for QCs at low, mid and high concentrations. Accepted ratio is $67 \%$ of each level and $67 \%$ for the total.

\subsubsection{Absolute Analytical Recovery}

The detector response obtained from the injection of the extracted QC samples was compared to the detector response of an equivalent pure authentic standard solution that was prepared to contain a drug and internal standard concentration assuming $100 \%$ recovery and reconstituted in dry extracted blank samples from six different batches. The absolute recoveries were calculated for Clopidogrel carboxylic acid and internal standards by comparing the relevant peak areas of the extracted QC samples with the 
peak areas of an equivalent un-extracted pure authentic standard solution reconstitute in the dry extracted blank samples. The absolute analytical recovery was calculated for Clopidogrel carboxylic acid at three concentration levels $(75,1500$ and 2250) $\mathrm{ng} / \mathrm{ml}$, while for the internal standard, absolute analytical recovery was calculated at the nominal concentration of $500 \mathrm{ng} / \mathrm{ml}$ for Clopidogrel-d4-carboxylic acid

Acceptance criteria: Recovery close to $100 \%$ are desirable, the extent of absolute analytical recovery of an analyte and/or the internal standard may be as low as $50 \%$ to $60 \%$ but not more than $110 \%$; if the recovery is precise, accurate, and reproducible.

\subsubsection{Sensitivity}

The lowest standard concentration in the calibration curve is considered as the lower limit of quantification (LLOQ) that meets the following acceptance criteria:

LLOQ response is five times the response of the blank sample.

The sensitivity was tested by preparing and analyzing six QC samples at the LLOQ with a complete set of calibration curve on each day of the three days of validation.

\subsubsection{Stability}

\subsubsection{Stability in Biological Plasma Samples}

The stability of Clopidogrel carboxylic acid and the internal standards (Clopidogrel-d4-carboxylic acid) was studied using six QC samples for each time interval session, at both the low and the high concentration levels (75 and 2250) ng/ml Clopidogrel carboxylic acid.

1) Short-term stability

Sufficient number of QC samples at each concentration level were allocated to carry out the short-term stability. Six low and the high concentration levels were prepared and frozen at $-20^{\circ} \mathrm{C}$ for more than $12 \mathrm{hrs}$ then thawed at room temperature (RT) and left on the bench top at room temperature for 6 hours and then analyzed. Stability was calculated by comparing the tested QC samples with theoretical nominal concentrations.

Acceptance criteria: \% CV is within $\pm 15 \%$ for QCs at low and high concentrations. Accepted ratio is $67 \%$ of each level and $67 \%$ for the total, stability $\pm 15 \%$.

2) Maximum number of injections per run

The maximum number of injections per run is validated by injecting a standard calibration curve, and QC's at three levels (low, mid, high) in duplicate or more with blank samples spaced between the QC's. QC samples are distributed as the unknown samples in routine analysis.

The maximum number of injections per run was studied for 104 and it was passed.

4.1.5.2. Stock Solution Stability

Clopidogrel carboxylic acid and Clopidogrel-d4-carbox- ylic acid stock solution stability (prepared in methanol) were evaluated for 6 hours at room temperature, and for 23 days at $-20^{\circ} \mathrm{C}$.

Clopidogrel carboxylic acid and Colpidogre-d4-carboxylic acid working solution stability (prepared in de-ionized water) were evaluated for 6 hours at room temperature, and 10 days at $-20^{\circ} \mathrm{C}$.

Stability was calculated by comparing the pertinent responses obtained from the test stock solutions(s) with the responses of freshly prepared ones.

\subsubsection{Matrix Dilution Integrity}

Samples of concentration higher than ULOQ should be diluted with a complementary volume of the same biological matrix. Thus, the resultant dilute sample would be processed and the obtained area ratio can be easily fitted to the regression equation of the calibration curve. The dilution should bring down the concentration to fall within the linear range.

Acceptance criteria: \% CV and accuracy should be within $\pm 15 \%$ for QC dilution and the accepted ratio is $67 \%$ per level.

\section{Result}

\subsection{Mass Spectrometry and Chromatography}

The MRM chromatograms of Clopidogrel carboxylic acid and Clopidogrel-d4-carboxylic acid obtained by extraction of human plasma are shown in (Figures 2-5). The retention times for Clopidogrel and internal standard was 1.82. No endogenous or extraneous peaks interfered with the assy. The lower limit of quantification of Clopidogrel carboxylic acid was $25 \mathrm{ng} / \mathrm{ml}$. the calibration curve was linear over a concentration from 25 - 3000 $\mathrm{ng} / \mathrm{ml}$. In this study, matrix matched standards were used in constructing the calibration curve, therefore, any possible indirect interference caused by the endogenous components was minimized.

\subsection{Method Validation}

Specificity of the method was verified by the absence of any co-eluted peaks of endogenous plasma component at the retention times of the drug or the internal standard. All samples passed the acceptance criteria. The chromatogram for a blank plasma sample indicating that the method is specific, and the results of the six LLOQ shows that there is no matrix effect on LLOQ (Figure 2). The method is linear over the range $(25-3000) \mathrm{ng} / \mathrm{ml}$ for Clopidogrel carboxylic acid, $(r \geq 0.999)$, where at the LLOQ accuracy obtained was 94\% (less than 20\% deviation) and $96.76 \%$ - $103 \%$ for standard points higher than 
$0.025 / 25 \mathrm{ng} / \mathrm{ml}$-Clopidogrel carboxylic acid (QC) 308.1/113.0

amu - 230509D009.wiff

Area: 109142 counts Height: $1.164 \mathrm{e}+004 \mathrm{cps}$ RT: $1.82 \mathrm{~min}$

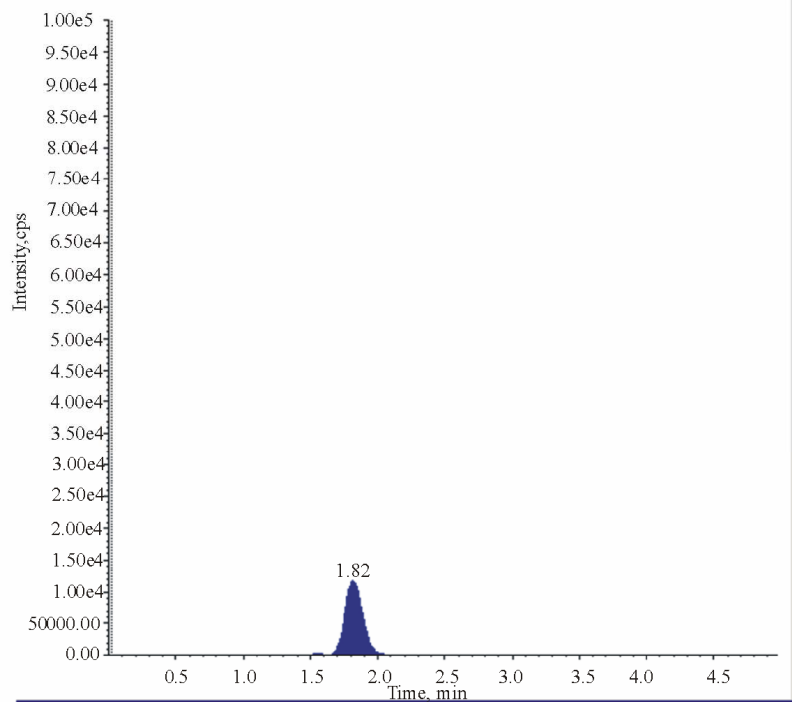

Clopidogrel d4 carboxylic acid(IS) (QC) 312.1/129.0 amu -

230509D019.wiff

Area: 2469344 counts Height: $2.66 \mathrm{e}+005 \mathrm{cps}$ RT: $1.82 \mathrm{~min}$

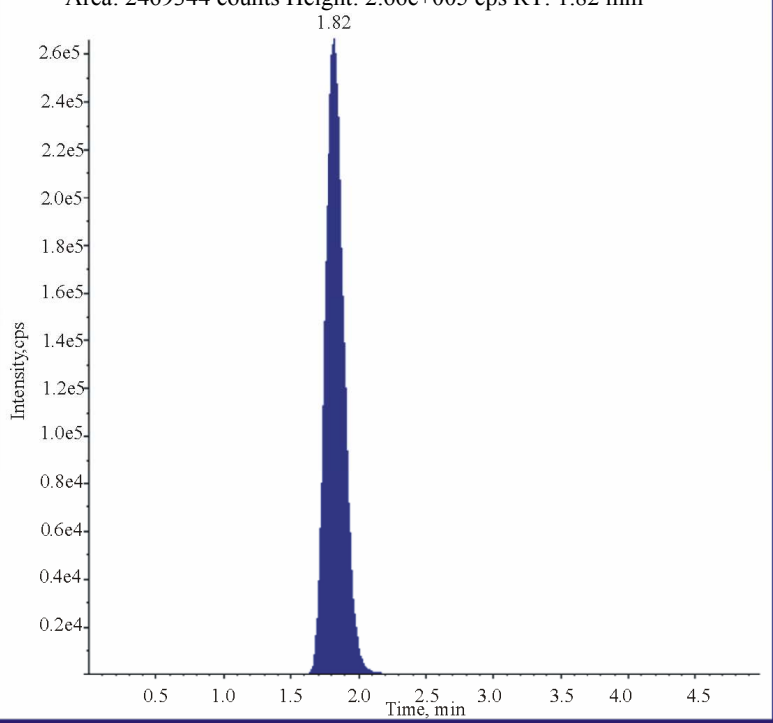

Figure 2. LC/MS/MS chromatogram showing human plasma containing 25 ng/ml Clopidogrel carboxylic acid (LLOQ) and $500 \mathrm{ng} / \mathrm{ml}$ internal standard (Clopidogrel-d4-carboxylic acid).
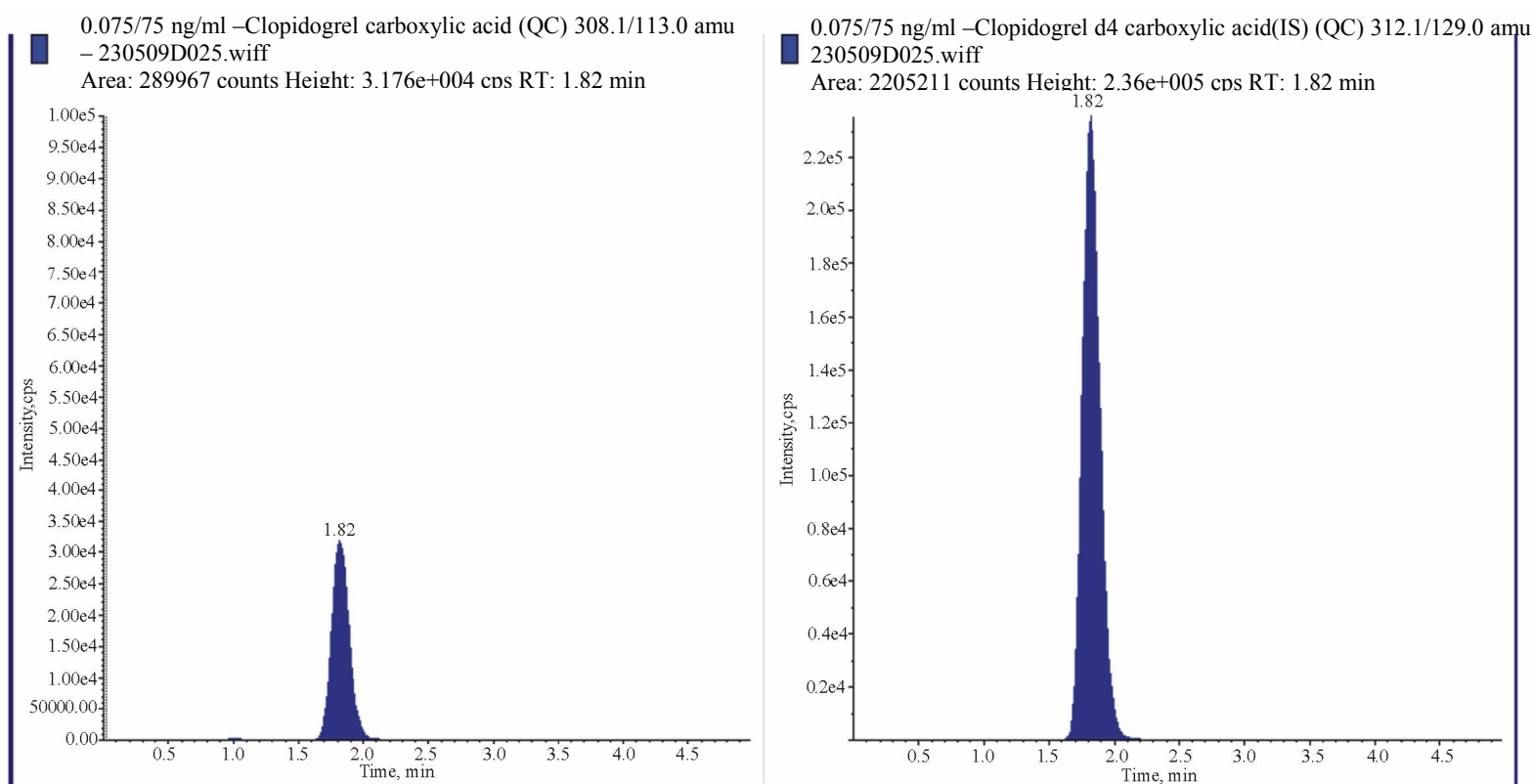

Figure 3. LC/MS/MS chromatogram showing human plasma containing $75 \mathrm{ng} / \mathrm{ml}$ Clopidogrel carboxylic acid (QC LOW) and $500 \mathrm{ng} / \mathrm{ml}$ internal standard (Clopidogrel-d4-carboxylic acid).

LLOQ (less than $15 \%$ deviation), and $75 \%$ ratio of total standard points were accepted. LLOQ response is identifiable, discrete and reproducible with precision and accuracy of $\pm 20 \%$. The peak is identifiable, precise and accurate at this concentration. The intra- and inter-day accuracies were $90 \%$ - 98\% for LLOQ and $92.138 \%$ $96.889 \%$ for QC's above LLOQ respectively, and the intra- and inter-day precisions were $2.43 \%-5 \%$ for LLOQ and 1.31-2.64 for QC's above LLOQ and 5.47\% for LLOQ and 1.40-2.64 for QC's above LLOQ respectively (Table 1). This Results support the fact that the method is accurate and precise, where deviations obtained were less than $20 \%$ for LLOQ and less than $15 \%$ for the QC's above the LLOQ. The average extraction recoveries of Clopidogrel carboxylic acid determined at 75,1500 and $2250 \mathrm{ng} / \mathrm{ml}$ were $67.57,73.51$ and 69.03 respectively (Table 2), while that of internal standard determined at $500 \mathrm{ng} / \mathrm{ml}$ was $70.91,74.46$ and 68.66 res- 
$3.000 / 1500 \mathrm{ng} / \mathrm{ml}$-Clopidogrel carboxylic acid (QC) 308.1/113.0 amu

230509D031.wiff

Area: 5234674 counts Height: $5.397 \mathrm{e}+005$ cps RT: $1.82 \mathrm{~min}$

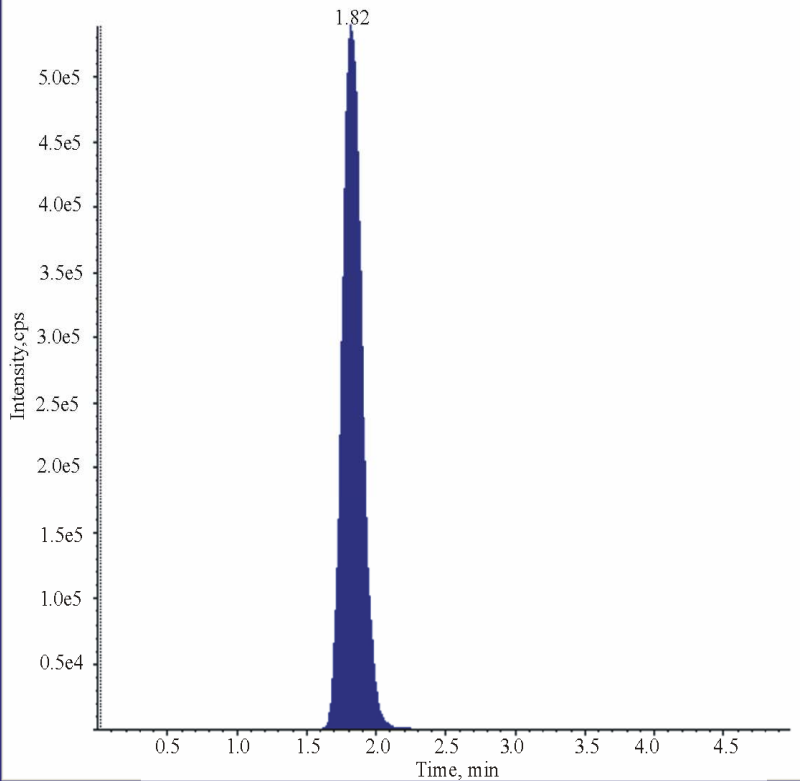

Clopidogrel d4 carboxylic acid(IS) (QC) 312.1/129.0 amu230509D031.wiff

Area: 2329774 counts Height: $2.48 \mathrm{e}+005 \mathrm{cps}$ RT: $1.82 \mathrm{~min}$

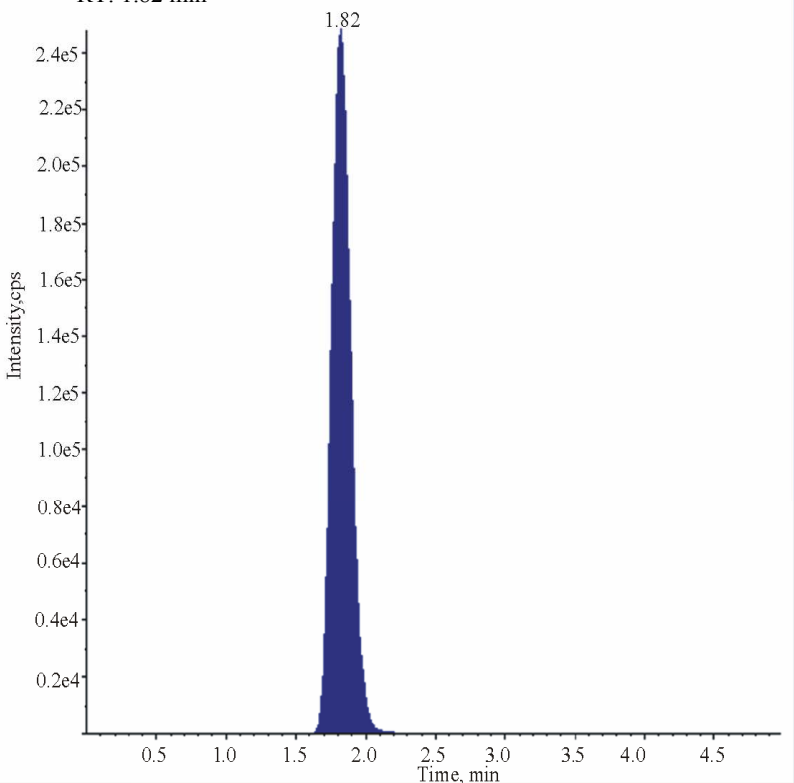

Figure 4. LC/MS/MS chromatogram showing human plasma sample containing $1500 \mathrm{ng} / \mathrm{ml}$ Clopidogrel carboxylic acid (QC Medium) and $500 \mathrm{ng} / \mathrm{ml}$ internal standard (Clopidogrel-d4-carboxylic acid) . 230509D037.wiff

Area: 6294723 counts Height: $6.374 \mathrm{e}+005 \mathrm{cps}$ RT: $1.82 \mathrm{~min}$

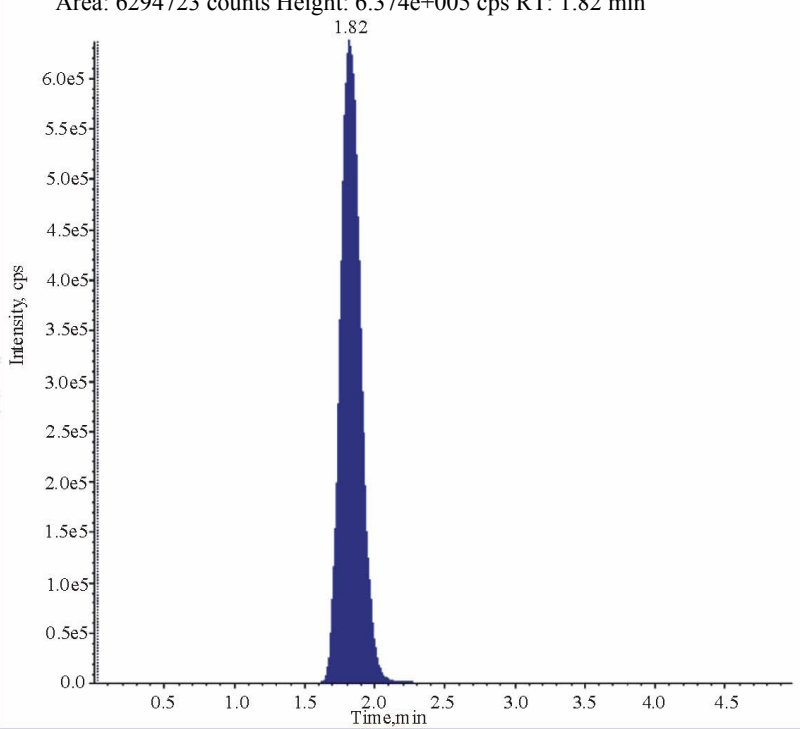

4.500/2250 ng/ml -Clopidogrel carboxylic acid (QC) 308.1/113.0 amu 230509D037.wiff

Area: 6294723 counts Height: $6.374 \mathrm{e}+005$ cps RT: $1.82 \mathrm{~min}$

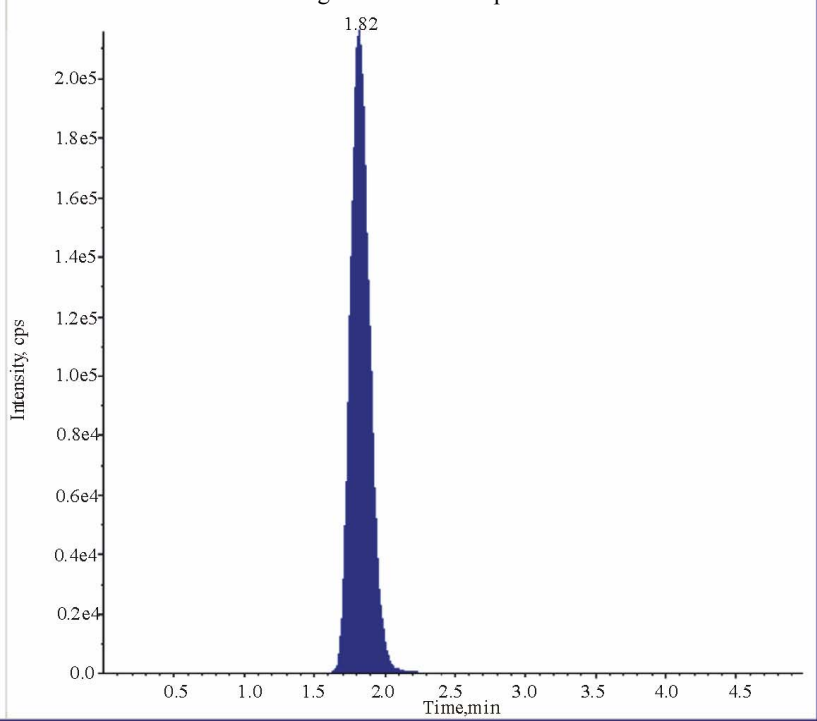

Figure 5. LC/MS/MS chromatogram showing human plasma containing $2250 \mathrm{ng} / \mathrm{ml}$ Clopidogrel carboxylic acid (QC High) and $500 \mathrm{ng} / \mathrm{ml}$ internal standard (Clopidogrel-d4-carboxylic acid).

pectively with high degree of precision, accuracy and reproducibility. Clopidogrel carboxylic acid is stable up to 6 hours at room temperature as supported by the $\% \mathrm{CV}$ obtained $(2.12 \%)$ for the low concentration $(75 \mathrm{ng} / \mathrm{ml})$ and $(1.35 \%)$ for the high concentration $(2250 \mathrm{ng} / \mathrm{ml})$ for all the QC samples. The method has shown that the stock solution for Clopidogrel carboxylic acid and Clopidogrel d4-carboxylic acid in methanol is stable for 6 hours at room temperature and up to 23 days at $-20^{\circ} \mathrm{C}$, while that for the serial solution in de-ionized water is 6 hours at room temperature and up to 10 days at $-20^{\circ} \mathrm{C}$. Clopidogrel carboxylic acid was stable with absolute percentages 
Table 1. Accuracy and precision for the analysis of Clopidogrel carboxylic acid in human plasma obtained after analysis of three days with six replicates per day.

\begin{tabular}{|c|c|c|c|c|c|c|}
\hline \multirow{2}{*}{$\frac{\mathrm{QC}}{\mathrm{ng} / \mathrm{ml}}$} & \multicolumn{3}{|c|}{$\begin{array}{l}\text { Intra-day mean }( \pm \mathrm{SD}) \text { concentrations } \\
\text { (intra-day } \mathrm{CV} \%) \mathrm{ng} / \mathrm{ml}\end{array}$} & \multirow{2}{*}{$\begin{array}{c}\text { Inter-day mean } \\
\text { concentration } \\
\mathrm{ng} / \mathrm{ml} \pm \mathrm{SD}\end{array}$} & \multirow{2}{*}{$\begin{array}{l}\text { Inter-day } \\
\text { CV \% }\end{array}$} & \multirow{2}{*}{ Accuracy $\%$} \\
\hline & Day 1 & Day2 & Day 3 & & & \\
\hline $\begin{array}{l}\text { QC LLOQ } 25 \\
\mathrm{ng} / \mathrm{ml}\end{array}$ & $\begin{array}{l}24.5 \pm 1.2 \\
(5)\end{array}$ & $\begin{array}{c}22.8 \pm 1 \\
(4.31)\end{array}$ & $\begin{array}{l}22.5 \pm 0.5 \\
\quad(2.43)\end{array}$ & $23.3 \pm 1.3$ & 5.47 & 93.111 \\
\hline $\begin{array}{l}\text { QC Low } 75 \\
\mathrm{ng} / \mathrm{ml}\end{array}$ & $\begin{array}{c}72.8 \pm 1.3 \\
(1.82)\end{array}$ & $\begin{array}{c}72.8 \pm 1.2 \\
(1.61)\end{array}$ & $\begin{array}{c}72.3 \pm 1.4 \\
(1.89)\end{array}$ & $72.7 \pm 1.2$ & 1.70 & 96.889 \\
\hline $\begin{array}{l}\text { QC Mid } 1500 \\
\mathrm{ng} / \mathrm{ml}\end{array}$ & $\begin{array}{c}1404.2 \pm 20.6 \\
(1.46)\end{array}$ & $\begin{array}{c}1403.5 \pm 19.7 \\
(1.40)\end{array}$ & $\begin{array}{c}1418.3 \pm 18.6 \\
(1.31)\end{array}$ & $1408.7 \pm 19.8$ & 1.40 & 93.911 \\
\hline $\begin{array}{l}\text { QC High } 2250 \\
\mathrm{ng} / \mathrm{ml}\end{array}$ & $\begin{array}{l}2033.2 \pm 53.8 \\
(2.64)\end{array}$ & $\begin{array}{l}2088.2 \pm 55.8 \\
\quad(2.67)\end{array}$ & $\begin{array}{l}2098 \pm 34.9 \\
\quad(1.66)\end{array}$ & $2073.1 \pm 54.6$ & 2.64 & 92.138 \\
\hline
\end{tabular}

Table 2. Extraction recovery data of Clopidogrel carboxylic acid in human plasma $(n=6)$.

\begin{tabular}{cccc}
\hline $\begin{array}{c}\text { Spiked } \\
\text { Concentration } \mathrm{ng} / \mathrm{ml}\end{array}$ & $\begin{array}{c}\text { Extraction } \\
\text { recovery\% }\end{array}$ & $\begin{array}{c}\text { Mean } \\
\text { recovery\% }\end{array}$ & SD \\
\hline 75 & 67.57 & & \\
1500 & 73.51 & 70.037 & 3.059 \\
2250 & 69.03 & & 4.42 \\
\hline
\end{tabular}

number of replicates

of deviation of calculated vs theoretical concentration being less than $15 \%$ for stock solution, auto sampler, freeze-thaw, short-term and long-term stabilities determined at three concentrations of 75,1500 and 2250 $\mathrm{ng} / \mathrm{ml}$. The stability was within the limit of $85.00 \%$ $115.00 \%$ \& the CV\% less than $15.00 \%$. The method has shown that the dilution factor of $(3,4)$ for Clopidogrel carboxylic acid concentration $(6000,9000) \mathrm{ng} / \mathrm{ml}$ is precise since the obtained $\mathrm{CV} \%$ was $1.18 \& 1.01$.

\section{Discussion}

Several analytical methods have been reported for determination of Clopidogrel carboxylic acid in biological fluids. A sensitive GC/MS method with LOQ of $5 \mathrm{ng} / \mathrm{ml}$ has been published [23]. In this method, a complex two steps extraction method using both liquid-liquid and solid phase extraction procedures as well as derivatization of the analyte are required. LC/UV method for determination of clopidogerel carboxylic acid in Wistar rat plasma has been reported using HPLC and UV detection [24]. In this method however, LOQ of $125 \mathrm{ng} / \mathrm{mL}$ has been reported using $50 \mu \mathrm{L}$ injection. Furthermore, this method involves long run time of analysis $(16 \mathrm{~min})$ and gradient elution of the mobile phase. In HPLC-UV technique described by Souri et al. [25] ticlopidine has been used as internal standard. To overcome close retention times of clopidogrel carboxylic acid and ticlopidine, they used a mobile phase with low flow rate $(0.9 \mathrm{~mL} / \mathrm{min})$ and high percent of aqueous phase which leads to long analytical run time $(12 \mathrm{~min})$ and reduction of sensitivity (LOQ $0.2 \mu \mathrm{g} / \mathrm{mL}$ ). Two LC-MS methods [10,28] have been reported for the determination of Clopidogrel car- boxylic acid in plasma. In the method described by Mitakos and Panderi [28], extraction of the analyte from the serum has been achieved using single step solid phase extraction however, their method is not sensitive enough (LOQ $100 \mathrm{ng} / \mathrm{mL}$ ) to be used in single-dose pharmacokinetic studies of the drug. In the other published LC-MS method by Ksycinska et al. [10] two steps time-consuming extraction procedure using both liquid-liquid and solid phase extraction techniques have been used however, the method is sensitive enough (LLOQ $20 \mathrm{ng} / \mathrm{mL}$ ) for measuring of the analyte up to at least three half lives post-dose. To improve run time and sensitivity of the analysis, the flow rate should be increased and it is preferred to select a mobile phase with higher proportion of organic solvent. LC/MS/MS methods [16,29-31] have been reported for the determination of clopidogrel in plasma . Taubert et al. [32] reported an LC/MS/MS method for the simultaneous quantification of clopidogrel and its carboxylic acid in human plasma, in which no internal standards were used. Recently, Mani et al. [33] and Abib E et al. [34] developed a LC/MS/MS method for the simultaneous determination of clopidogrel carboxylic acid in human plasma, with the LLOQ of 25 and $10 \mathrm{ng} / \mathrm{mL}$ respectively, but the employed procedure of solid-phase extraction (SPE) was complicated. In order to monitor the therapeutic drug in clopidogrel-treated patients, a more sensitive and simple method was required. In the present study, a sensitive LC/MS/MS method is reported for the simultaneous determination of clopidogrel carboxylic acid in human plasma. The internal standards were Clopidogrel-d4-carboxylic acid, and the LLOQ values of $25 \mathrm{ng} / \mathrm{mL}$ were found to be reproducible. The major advantages of the 
method are selectivity and sensitivity (LLOQ $25 \mathrm{ng} / \mathrm{ml}$ ) reduction in run time of analysis (4.0 $\mathrm{min}$ ) which allows determination of the analyte more precisely. Representative chromatograms are shown in Figures 2-5. All samples were found to show no interference at the retention times of the analytes.

\section{Conclusions}

The developed method showed a linear dynamic range of 25-3000 ng/ml, with good intra-and inter-day accuracy and precision. It was shown that this method is suitable for pharmacokinetic study following oral administration of Clopidogrel to male volunteers under fasting conditions. The method has been successfully applied to the therapeutic drug monitoring of clopidogrel in clopidogrel-treated patients. The LLOQ of the assay was sufficient to characterize the absorption kinetics of Clopidogrel in human.

\section{References}

[1] D. C. Mills, R. Puri, C. J. Hu, C. Minniti, G. Grana, M. D. Freedman, R. F. Colman and R. W. Colman, "Clopidogrel Inhibits the Binding of ADP Analogues to the Receptor Mediating Inhibition of Platelet Adenylate Cyclase," Arteriosclerosis Thrombosis, Vol. 12, No. 4, 1992, pp. 430-436. doi:10.1161/01.ATV.12.4.430

[2] P. W. Majerus and D. M. Tollefsen, "Blood Coagulation and Anticoagulant, Thrombolytic, and Antiplatelet Drugs," In: L. L. Brunton, Ed., The Pharmacological Basis of Therapeutics, 11th Edition, The McGraw-Hill Companies, New York, 2006, p. 1483.

[3] PLAVIXTM, 2011. www.RXlist.com

[4] Safety, 2011. http://www.fda.gov/medwatch/safety/2007/May_PI/Plavi x_PI.pdf

[5] P. Savi, J. Combalbert, C. Gaich, M. C. Rouchon, J. P. Maffrand, Y. Berger and J. M. Herbert, "The Antiaggregating Activity of Clopidogrel Is Due to a Metabolic Activation by the Hepatic Cytochrome P450-1A," Thromb Haemostasis, Vol. 72, 1994, pp. 313-317.

[6] J. M. Pereillo, M. Maftouh, A. Andrieu, M. F. Uzabiaga, O. Fedeli, P. Savi, M. Pascal, J. M. Herbert, J. P. Maffrand and C. Picard, "Structure and Stereochemistry of the Active Metabolite of Clopidogrel," Drug Metabolism and Disposition, Vol. 30, No. 11, 2002, pp. 1288-1295. doi:10.1124/dmd.30.11.1288

[7] Y. Gomez, E. Adams and J. Hoogmartens, "Analysis of Purity in 19 Drug Product Tablets Containing Clopidogrel: 18 Copies Versus Theoriginal Brand," Journal of Pharmaceutical and Biomedical Analysis, Vol. 34, No. 2, 2004, pp. 341-348.

[8] J. M. Herbert, D. Frehel, E. Vallee, G. Kieffer, D. Gouy, Y. Berger, G. Defreyn and J. P. Maffrand, "Clopidogrel, a Novel Antiplateletand Antithrombotic Agent," Cardio- vascular Drugs, Vol. 11, No. 2, 1993, pp. 180-198.

[9] T. R. Rao, P. R. Usha, M. U. Naidu, J. A. Gogtay and M. Meena, "Bioequivalence and Tolerability Study of Two Brands of Clopidogrel Tablets, Using Inhibition of Platelet Aggregation and Pharmacodynamic Measures," Current Therapeutic Research, Vol. 64, No. 9, 2003, pp. 685696. doi:10.1016/j.curtheres.2003.09.014

[10] H. Ksycinska, P. Rudzki and M. Bukowska-Kiliszek, "Determination of Clopidogrel Metabolite (SR26334) in Human Plasma by LC-MS," Journal of Pharmaceutical and Biomedical Analysis, Vol. 41, No. 2, 2006, pp. 533539. doi:10.1016/j.jpba.2005.11.035

[11] P. C. A. Kam and C. M. Nethery, "The Thienopyridine Derivatives (Platelet Adenosine Diphosphate Receptor Antagonists), Pharmacology and Clinical Developments," Anaesthesia, Vol. 58, No. 1, 2008, pp. 28-35. doi:10.1046/j.1365-2044.2003.02960.x

[12] J. McEwen, G. Strauch, P. Perles, G. Fowter, T. Moreland, J. P. Dickinson, R. Meontels, J. Mosser and J. Neccian, "Clopidogrel Bioavailability Is Unaffected by Food or Antacids," The Journal of Clinical Pharmacology, Vol. 36, No. 9, 1996, p. 856.

[13] G. Vilahur, B. G. Choi, M. U. Zafar, J. F. Viles-Gonzalez, D. A. Vorchheimer, V. Fuster and J. J. Badimon, "Normalization of Platelet Reactivity in Clopidogrel-Treated Subjects," Journal of Thrombosis and Haemostasis, Vol. 5, No. 1, 2007, pp. 82-90. doi:10.1111/j.1538-7836.2006.02245.x

[14] R. H. Hongo, J. Ley, S. E. Dick and R. R. Yee, "The Effect of Clopidogrel in Combination with Aspirin When Given before Coronary Artery Bypass Grafting," Journal of the American College of Cardiology, Vol. 40, No. 2, 2002, pp. 231-237. doi:10.1016/S0735-1097(02)01954-X

[15] K. A. Kim, P. W. Park and J. Y. Park, "Effect of CYP3A5*3 Genotype on the Pharmacokinetics and Antiplatelet Effect of Clopidogrel in Healthy Subjects," European Journal of Clinical Pharmacology, Vol. 64, No. 6, 2008, pp. 589-597. doi:10.1007/s00228-008-0471-0

[16] R. V. S. Nirogi, V. N. Kandikere, M. Shukla, K. Mudigonda, S. Maurya and R. Boosi, "Quantification of Clopidogrel in Human Plasma by Sensitive Liquid Chromatography/Tandem Mass Spectrometry," Mass Spectrometry, Vol. 20, No. 11, 2006, pp. 1695-1700.

[17] R. A. Kulkarni, "Clopidogrel in Cardiovascular Disorders," Journal of Postgraduate Medicine, Vol. 46, No. 4, 2000, pp. 312-313.

[18] G. Escolar and M. Heras, "Clopidogrel: A Selective Inhibitor of Platelet ADP Receptors," Drugs Today, Vol. 36, No. 4, 2000, p. 187.

[19] A. A. Weber, S. Reimann and K. Schrör, "Specific Inhibition of ADP Induced Platelet Aggregation by Clopidogrel in Vitro," British Journal of Pharmacology, Vol. 126, No. 2, 1999, pp. 415-420. doi:10.1038/sj.bjp.0702276

[20] K. Schrör. "The Basic Pharmacology of Ticlopidine and Clopidogrel," Platelets, Vol. 4, No. 5, 1993, pp. 252-261. doi: $10.3109 / 09537109309013225$

[21] P. A. Gurbel, C. M. O'Connor, C. C. Cummings and V. L. 
Serebruany, "Clopidogrel: The Future Choice for Preventing Platelet Activationduring Coronary Stenting?" Pharmacological Research, Vol. 40, No. 2, 1999, pp. 107-111. doi:10.1006/phrs.1999.0478

[22] CAPRIE Steering Committee, “A Randomized Blinded Trial of Clopidogrel versus Aspirin in Patients at Risk of Ischemic Events (CAPRIE)," Lancet, Vol. 348, No. 9038, 1996, pp. 1329-1339. doi:10.1016/S0140-6736(96)09457-3

[23] P. Lagorce, Y. Perez, J. Ortiz, J. Necciari and F. Bressolle, "Assay Method for the Carboxylic Acid Metabolite of Clopidogrel in Human Plasma by Gas Chromatography-Mass Spectrometry," Journal of Chromatography B: Biomedical Sciences, Vol. 720, No. 1-2, 1998, pp. 107117. doi:10.1016/S0378-4347(98)00452-6

[24] S. S. Singh, K. Sharma, D. Barot, P. R. Mohan and V. B. Lohray, "Estimation of Carboxylic Acid Metabolite of Clopidogrel in Wistar Rat Plasma by HPLC and Its Application to a Pharmacokinetic Study," Journal of Chromatography B. Analytical Technologies in the Biomedical and Life Sciences, Vol. 821, No. 2, 2005, pp. 173-180. doi:10.1016/j.jchromb.2005.05.013

[25] E. Souri, H. Jalalizadeh, A. Kebriaee-Zadeh, M. Shekarchi and A. Dalvandi, "Validated HPLC Method for Determination of Carboxylic Acid Metabolite of Clopidogrel in Human Plasma and Its Application to a Pharmacokinetic Study," Biomedical Chromatography, Vol. 20, 2006, pp. 1309-1314. doi:10.1002/bmc.697

[26] ICH Steering Committee, "Validation of Analytical Procedures: Methodology," 1996. http://www.pharmweb.net/pomirroor/pw9/ifpma/ichl.htm 1

[27] U.S. Department of Health and Human Services, Food and Drug Administration, Center for Drug Evaluation and Research (CDER), Center for Veterinary Medicine (CVM), "Guidance for Industry: Bioanalytical Method Validation,” May 2001.
[28] A. Mitakos and I. Panderi, "Determination of the Carboxylic Acid Metabolite of Clopidogrel in Human Plasma by Liquid Chromatography-Electrospray Ionization Mass Spectrometry," Analytica Chimica Acta, Vol. 505, No. 1, 2004, pp. 107-114. doi:10.1016/S0003-2670(03)00019-9

[29] A. Robinson, J. Hillis, C. Neal and A. C. Leary, "The Validation of a Bioanalytical Method for the Determination of Clopidogrel in Human Plasma," Journal of Chromatography B, Vol. 848, No. 2, 2007, pp. 344-354. doi:10.1016/j.jchromb.2006.10.076

[30] A. Lainesse, Y. Ozalp, H. Wong and R. S. Alpan, "Bioequivalence Study of Clopidogrel Bisulfate Film-Coated Tablets," Arzneimittelforshung, Vol. 54, No. 9, 2004, pp. 600-604.

[31] B. S. Shin and S. D. Yoo "Determination of Clopidogrel in Human Plasma by Liquid Chromatography/Tandem Mass Spectrometry: Application to a Clinical Pharmacokinetic Study," Biomedical Chromatography, Vol. 21, No. 9, 2007, pp. 883-889. doi:10.1002/bmc.850

[32] D. Taubert, A. Kastrati, S. Harlfinger, O. Gorchakova, A. Lazar, N. Beckerath, A. Schomong and E.Schomig, "Pharmacokinetics of Clopidogrel after Administration of a High Loading Dose," Thromb Haemostasis, Vol. 92, 2004, pp. 311-316.

[33] H. Mani, S. W. Toennes, B. Linnemann, D. A. Urbanek, J. Schwonberg, G. F. Kauert and E. Lindhoff-Last, "Determination of Clopidogrel Main Metabolite in Plasma: A Useful Tool for Monitoring Therapy?" Therapeutic Drug Monitoring, Vol. 30, No. 1, 2008, pp. 84-89. doi:10.1097/FTD.0b013e31815c13fd

[34] E. Abib, L. F. Duarte, M. L. P. Vanunci, D. A. Oliveira de, S. Antonelli, et al., "Comparative Biological Availability of Clopidogrel Formulation in Healthy Volunteers After a Single Dose Administration," Journal of Bioequivalence \& Bioavailability, Vol. 2, No. 2, 2010, pp. 45-49. 